\title{
Distal chronic spinal muscular atrophy involving the hands
}

\author{
D. J. O'S ULLIVAN AND J. G. M C LEOD \\ From St Vincent's Hospital, and Department of Medicine, University of Sydney, New South Wales \\ Australia
}

SUMMARY Six patients are described with a history of slowly progressive wasting of the muscle of the hands and forearms extending over periods of up to 20 years. The clinical, radiological, and electrophysiological findings were consistent with a diagnosis of chronic anterior horn cell degeneration. It is suggested that the patients are affected by a form of distal chronic spinal muscular atrophy affecting the hands.

The spinal muscular atrophies are a group of genetically determined disorders in which the primary defect is degeneration of the anterior horn cells of the spinal cord and often of the bulbar motor nuclei. The more common chronic form usually involves proximal muscles (Kugelberg and Welander, 1956), but a rarer form involving the distal muscles of the lower limbs has been described (Dyck and Lambert, 1968; Meadows and Marsden, 1969; McLeod and Prineas, 1971). The purpose of the present report is to describe the clinical and electrophysiological features of six patients with a localised benign form of chronic spinal muscular atrophy affecting the small muscles of the hands, and in some cases the forearms.

\section{Methods}

\section{ELECTROPHYSIOLOGICAL TECHNIQUES}

Electromyography was performed on muscles of the upper and lower limbs with concentric needle electrodes. Motor conduction velocities were measured in the median, ulnar, and lateral popliteal nerves by employing standard techniques using concentric needle electrodes. Sensory action potentials were recorded with surface electrodes from the median and ulnar nerves at the wrist on stimulating the index and little fingers respectively through ring electrodes (Dawson, 1956).

Address for reprint requests: Professor J. G. McLeod, Department of Medicine, University of Sydney, New South Wales 2006, Australia.

Accepted 15 February 1978

\section{Case reports}

\section{CASE 1}

A woman (PC), aged 40 years, had been aware of difficulty with writing since childhood. Nine years ago she developed pain radiating from the shoulders to the hands and, because of wasting of the thenar eminences, bilateral carpal tunnel surgery was performed. Over the last seven years she observed progressive wasting of the thenar and hypothenar eminences, although weakness of the hands has not prevented her from playing tennis regularly.

On physical examination, the abnormalities were confined to the upper limbs in which wasting and weakness of the intrinsic muscles of both hands were present but were more pronounced on the right side (Fig. 1). Power and development of other muscles was normal. Tendon reflexes were normal, and symmetrical and plantar responses were flexor. No sensory abnormalities were detected.

\section{Investigations}

Plain radiographs of the cervical spine and thoracic inlet, and a myelogram were normal. Full blood count, serum electrolytes and liver function tests, serum creatine, serum phosphokinase (CPK), serum aldolase, and cerebrospinal fluid (CSF) were all normal.

\section{Progress}

Over the last five years her clinical state has remained stationary. She is able to continue to play 


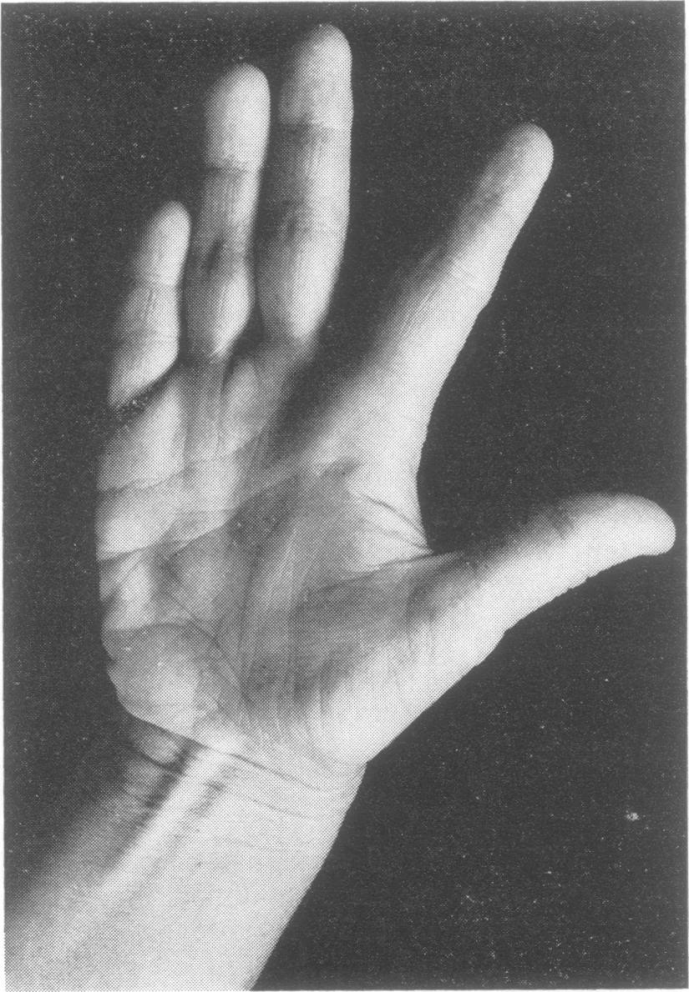

Fig. 1 Case 1. Wasting of the thenar and hypothenar muscles and of the interossei in right hand.

tennis regularly and manages her family without difficulty.

\section{Electrophysiology}

The right abductor pollicis brevis muscle was sampled with a concentric needle electrode. There was sparse spontaneous fibrillation. The pattern was reduced on maximum voluntary effort, with polyphasic unit potentials of amplitude up to $10 \mathrm{mV}$ firing in relative isolation. Similar abnormalities were found on sampling the right abductor digiti minimi muscle and the intrinsic muscles of the left hand. The right and left tibialis anterior muscles were sampled with a concentric needle electrode; no abnormalities were found.

The results of nerve conduction studies are summarised in the Table.

\section{CASE 2}

A man (BP), aged 25 years, presented with a history of very slow but progressive weakness and wasting of his distal arm muscles and small muscles of the hands for 16 years. There were no sensory symptoms. His paternal grandparents were first cousins.

On physical examination, the cranial nerves were intact. There was marked wasting and weakness of the thenar and hypothenar eminences and the interossei of both hands (Fig. 2). The other muscle groups were normal. The deep tendon reflexes were symmetrical and normally brisk, and the plantar responses were flexor. Sensory examination was normal.

\section{Investigations}

Full blood count, serum electrolytes, liver function tests, serum proteins, plasma electrophoretic pattern, CPK, serum aldolase, and CSF were normal. Plain radiographs of the cervical spine and thoracic inlet, and myelogram were normal.

\section{Progress}

His clinical state has remained virtually stationary over the last 10 years and there has been no evidence of involvement of other parts of the nervous system.

\section{Electrophysiology}

The left abductor digiti minimi, left abductor pollicis brevis, right first dorsal interosseous, and $\stackrel{\varnothing}{\circ}$ right abductor pollicis brevis muscles were sampled ${ }_{-} \rightarrow$ with a concentric needle electrode. There was no spontaneous fibrillation. The EMG pattern waso grossly reduced on maximum voluntary effort with polyphasic unit potentials of amplitude $15-20 \mathrm{mV}$ firing in relative isolation. Similar abnormalities were found on sampling the right forearm flexor, extensor muscles, and triceps.

The results of nerve conduction studies are shown in the Table.

\section{CASE 3}

A man (AY), aged 21 years, presented in 1968 with a history of weakness of his right hand. He had experienced no pain nor paraesthesiae. There was no relevant family history.

On physical examination there was marked wasting and weakness of all the intrinsic muscles of the right hand supplied by the ulnar nerve and to a lesser degree of the flexor carpi ulnaris. The reflexes were brisk and symmetrical, except for the right ankle jerk which was absent. There were no sensory abnormalities.

\section{Investigations}

Full blood count, serum electrolytes, and liver function tests were normal. Plain radiographs of the cervical spine and thoracic inlet were also normal. 
Table Summary of results of nerve conduction studies

\begin{tabular}{|c|c|c|c|c|c|c|c|c|c|c|c|}
\hline \multirow[b]{3}{*}{$\begin{array}{l}\text { Case } \\
\text { number }\end{array}$} & \multirow[b]{3}{*}{$\operatorname{Sex}$} & \multirow[b]{3}{*}{$\begin{array}{l}\text { Age } \\
(y r)\end{array}$} & \multirow[b]{3}{*}{ Clinical features } & \multirow[b]{3}{*}{$E M G$} & \multirow{2}{*}{\multicolumn{3}{|c|}{$\begin{array}{l}\text { Motor conduction } \\
(\mathrm{m} / \mathrm{s})\end{array}$}} & \multicolumn{4}{|c|}{ Sensory action potentials } \\
\hline & & & & & & & & \multicolumn{2}{|l|}{ Median } & \multicolumn{2}{|l|}{ Ulnar } \\
\hline & & & & & Median & Ulnar & $\begin{array}{l}\text { Lateral } \\
\text { popliteal }\end{array}$ & $\begin{array}{l}\text { Latency } \\
\text { (ms) }\end{array}$ & $\begin{array}{l}\text { Amplitude } \\
(\mu v)\end{array}$ & $\begin{array}{l}\text { Latency } \\
\text { (ms) }\end{array}$ & $\begin{array}{l}\text { Amplitude } \\
(\mu \nu)\end{array}$ \\
\hline 1 & $\mathbf{F}$ & 40 & $\begin{array}{l}\text { Difficulty with writing } \\
\text { since age } 10 \text { yr. Wasting } \\
\text { and weakness of intrinsic } \\
\text { muscles of both hands } \\
\text { right }>\text { left }\end{array}$ & $\begin{array}{l}\text { Chronic partial } \\
\text { denervation of } \\
\text { intrinsic muscles } \\
\text { of hands }\end{array}$ & 56 & 67 & 48 & 3.2 & 12 & 2.8 & 11 \\
\hline 2 & $\mathbf{M}$ & 25 & $\begin{array}{l}16 \mathrm{yr} \text { progressive } \\
\text { wasting and weakness } \\
\text { of distal muscles of } \\
\text { arms and small muscles } \\
\text { of hands }\end{array}$ & $\begin{array}{l}\text { Chronic partial } \\
\text { denervation of } \\
\text { small muscles of } \\
\text { both hands, right } \\
\text { forearm flexors, } \\
\text { extensors, and triceps }\end{array}$ & 59 & 51 & 47 & 4.0 & 17 & 3.3 & 18 \\
\hline 3 & $\mathbf{M}$ & 21 & $\begin{array}{l}\text { Six yr history of weak- } \\
\text { ness of his right hand. } \\
\text { Marked wasting and } \\
\text { weakness of ulnar } \\
\text { supplied muscles of } \\
\text { right hand }\end{array}$ & $\begin{array}{l}\text { Chronic partial } \\
\text { denervation of } \\
\text { small muscles of } \\
\text { right hand }\end{array}$ & 60 & 53 & 53 & 3.8 & 21 & 3.0 & 16 \\
\hline 4 & $\mathbf{M}$ & 40 & $\begin{array}{l}10 \mathrm{yr} \text { history of } \\
\text { progressive wasting and } \\
\text { weakness of small } \\
\text { muscles of right hand } \\
\text { and to a lesser degree } \\
\text { the left }\end{array}$ & $\begin{array}{l}\text { Chronic partial } \\
\text { denervation of } \\
\text { small muscles of } \\
\text { both hands and } \\
\text { right forearm } \\
\text { flexors }\end{array}$ & & 46 & & 3.2 & 20 & 3.1 & 11 \\
\hline 5 & $\mathbf{M}$ & 50 & $\begin{array}{l}22 \text { yr history of wasting } \\
\text { and weakness of right } \\
\text { hand. Wasting and } \\
\text { weakness of intrinsic } \\
\text { muscles of right hand, } \\
\text { weakness of right } \\
\text { triceps and extensors } \\
\text { of wrist }\end{array}$ & $\begin{array}{l}\text { Chronic partial } \\
\text { denervation of } \\
\text { small muscles of } \\
\text { right hand. } \\
\text { Normal sampling } \\
\text { of right triceps } \\
\text { and biceps muscles }\end{array}$ & 30 & 50 & & 2.2 & 15 & 2.2 & 7 \\
\hline 6 & $\mathbf{F}$ & 57 & $\begin{array}{l}\text { Weakness left thumb } \\
\text { for } 30 \text { yr. Wasting and } \\
\text { weakness of intrinsic } \\
\text { muscles of left hand, } \\
\text { weakness of finger } \\
\text { extensors, mild } \\
\text { weakness wrist } \\
\text { extensors and flexors }\end{array}$ & $\begin{array}{l}\text { Chronic partial } \\
\text { denervation of } \\
\text { small muscles } \\
\text { of left hand, both } \\
\text { quadriceps and } \\
\text { right abductor } \\
\text { pollicis brevis }\end{array}$ & 62 & 65 & & 3.0 & 20 & 3.0 & 15 \\
\hline
\end{tabular}

Progress

His clinical state has remained stationary, and he continues to work as a nurse.

\section{Electrophysiology}

The right first dorsal interosseous muscle and the right abductor pollicis brevis muscles were sampled with a concentric needle electrode. There was no spontaneous fibrillation; the pattern was markedly reduced on maximal voluntary effort with polyphasic unit potentials of increased amplitude and long duration firing in relative isolation.

Nerve conduction studies were normal (see Table). There was no evidence of an ulnar nerve lesion.

CASE 4

A man (RMcB), aged 40 years, presented in 1969 with a 10 year history of progressive wasting and weakness of the muscles of the right hand. There was no relevant family history.

On examination, the cranial nerves were intact, and there was no wasting or fasciculation of the tongue. There was severe wasting and weakness of the intrinsic muscles of the right hand and to a lesser degree of the left. The tendon reflexes were brisk and symmetrical, and the plantar responses were flexor. There was no sensory impairment.

\section{Investigations}

Full blood count and routine blood biochemical analyses were normal. Plain radiographs of the cervical spine and thoracic inlet, CSF examination, and myelogram were all normal.

\section{Progress}

There has been no progression of his neurological 


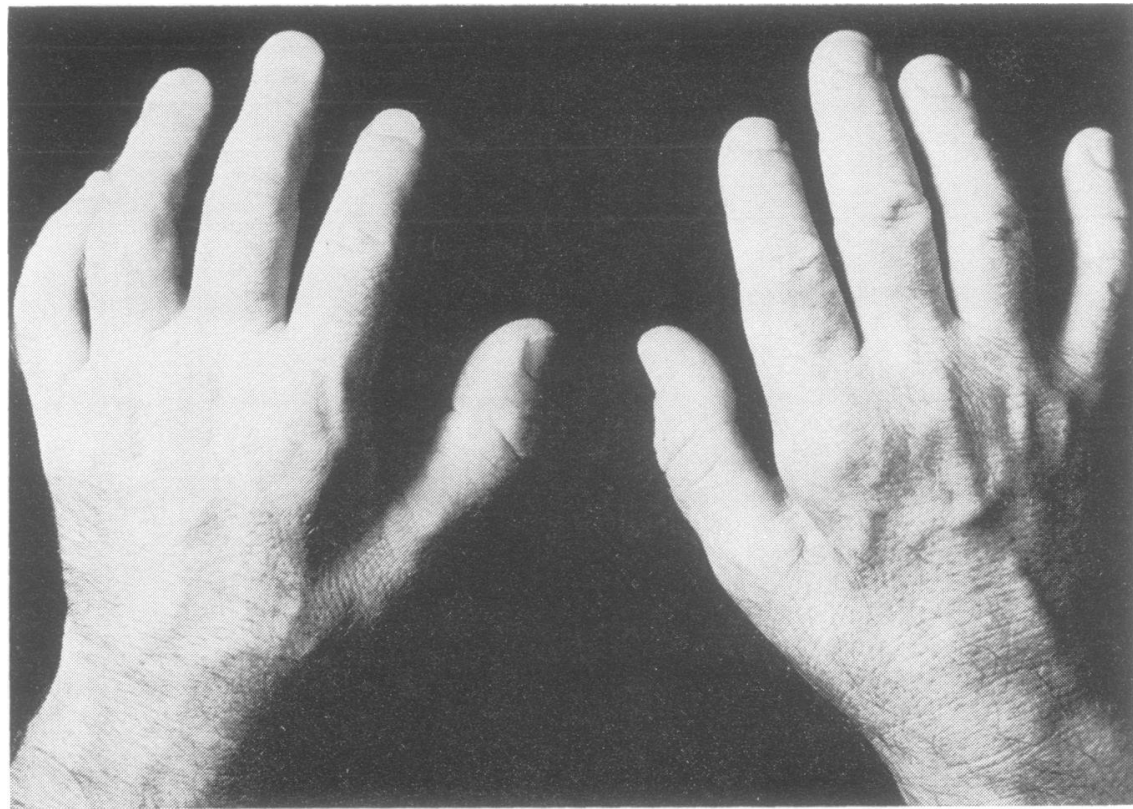

Fig. 2 Case 2. Wasting of interossei of both hands.

symptoms, and the abnormalities have remained confined to his right hand.

\section{Electrophysiology}

The right abductor digiti minimi and abductor pollicis brevis muscles, right forearm flexor muscles, and the left first dorsal interosseous muscles were sampled with a concentric needle electrode. There was no spontaneous fibrillation; the pattern was markedly reduced on maximum voluntary effort with polyphasic unit potentials of amplitude 5-6 mV and of long duration firing in relative isolation. Nerve conduction studies were normal and are summarised in the Table.

\section{CASE 5}

A man (FB), aged 50 years, first presented in 1957 with wasting and weakness of the right hand, but he had experienced no pain nor paraesthesiae. At that time a myelogram and the CSF were normal. Subsequently progression of symptoms occurred and scalenotomy was performed in 1967 without improvement.

On examination, the cranial nerves were intact. There was wasting and weakness of the intrinsic muscles of the right hand and weakness of the right triceps and wrist extensors. No abnormalities were found in the legs. The right triceps and finger jerks were absent but other tendon reflexes in the upper and lower limbs were normal, and the plantar responses were flexor. There were no abnormal sensory signs.
Investigations

Full blood count and routine blood biochemical analyses were normal. Plain radiographs of the cervical and thoracic spine were normal, and a myelogram and CSF studies were also normal.

\section{Progress}

He has been seen regularly since 1968 and little change has occurred.

\section{Electrophysiology}

The right first dorsal interosseous, right abductor digiti minimi, and right abductor pollicis brevis muscles were sampled with a concentric needle electrode. There was no spontaneous fibrillation. The pattern was markedly reduced on maximal voluntary effort with polyphasic unit potentials of amplitude 5-6 mV firing in relative isolation. No abnormality was found on sampling the right triceps and biceps muscles. Nerve conduction studies are summarised in the Table. Except for a right median motor nerve conduction velocity of $30 \mathrm{~m} / \mathrm{s}$, the results were normal.

\section{CASE 6}

A woman (MR), aged 57 years, first noticed weakness of her left thumb 30 years ago. In 1964 more pronounced weakness of her left hand became apparent, and by 1970 she experienced difficulty in holding a fork and supporting a cup of tea. In 1963 she had developed similar symptoms in her right hand, which were accompanied by 
pain and tingling; carpal tunnel decompression was performed and resulted in symptomatic improvement.

On examination the cranial nerves were intact. In the left upper limb there was wasting and weakness of the intrinsic muscles of the hand, definite weakness of finger extensors and mild weakness of the wrist extensors and the wrist flexors. Power and development in the other limbs were normal. Tendon reflexes were brisk and symmetrical and plantar responses were flexor. There were no objective sensory abnormalities.

\section{Investigations}

Full blood count, routine blood biochemistry examination, CSF and myelogram were normal.

\section{Progress}

The patient's clinical state has remained stationary for many years and the abnormal signs have been restricted to her left hand.

\section{Electrophysiology}

The left first dorsal interosseous and left abductor pollicis brevis muscles were sampled with a concentric needle electrode. There was no spontaneous fibrillation. The pattern was reduced on maximal voluntary effort with polyphasic unit potentials of long duration and increased amplitude firing in relative isolation. Similar but less pronounced abnormalities were found on sampling the right abductor pollicis brevis and the left and right quadriceps muscles.

Nerve conduction studies were normal and are summarised in the Table.

\section{Discussion}

In the six patients described in this report the clinical features of muscle wasting and weakness were virtually confined to the intrinsic muscles of the hands, except for case 5 , in whom there was mild weakness of the right triceps muscle and wrist extensors, and for case 6 in whom there was weakness of flexor and extensor muscle groups in the forearm. The history of both of these patients had extended beyond 20 years. In all patients the onset of symptoms was gradual and the course had been slowly progressive but with long periods during which the progress of the disability seemed to have arrested. The history does not seem compatible with a diagnosis of poliomyelitis. There was no family history to suggest a genetically determined disorder. In the three siblings described by Meadows and Marsden (1969), the onset of illness was similar to that of our patients but progression to a more diffuse form of chronic spinal muscular atrophy occurred with wasting and weakness in the proximal and distal muscles of the upper and lower limbs. Other causes of wasting of the small muscles of the hands include cervical rib, nerve root compression, and intrinsic spinal cord lesions such as syringomyelia and spinal cord tumour. However, the absence of sensory symptoms and signs and clinical manifestations of long tract involvement, and the normal radiological studies exclude these diagnoses.

The diagnostic possibilities which remain are peripheral nerve disease, distal myopathy, or chronic anterior horn cell disease. The electrophysiological findings of normal motor and sensory conduction in the presence of chronic partial denervation of the small muscles of the hand, and in some cases other muscles, are compatible only with the diagnosis of a chronic spinal muscular atrophy which affects mainly the hands. In case 5 the median nerve motor conduction velocity was $30 \mathrm{~m} / \mathrm{s}$; however, the wasting of the thenar eminence had been present for 20 years and the slowing of conduction was attributed to loss of large motor neurones. Although a slowly progressive form of amyotrophic lateral sclerosis with $10 \%$ survival beyond 10 years has been documented in long-term follow-up studies by Mulder and Howard (1976), the patients described in the present report differed from their cases in the absence of pyramidal tract signs, and confinement of the electrophysiological abnormalities to the muscles of the hands and forearms.

The electrophysiological and clinical abnormalities were confined to the muscles of the hands and arms in all patients except for case 6 in whom there was electrophysiological evidence of chronic partial denervation in the lower limbs. A distal form of chronic spinal muscular atrophy affecting the lower limbs has been described (Dyck and Lambert, 1968; Meadows and Marsden, 1969; McLeod and Prineas, 1971), and perhaps this patient represents a link between these two types of chronic spinal muscular atrophy.

\section{References}

Dawson, G. D. (1956). The relative excitability and conduction velocity of sensory and motor nerve fibres in man. Journal of Physiology, 131, 436-451.

Dyck, P. J., and Lambert, E. H. (1968). Lower motor and primary sensory neuron disease with peroneal muscular atrophy. Archives of Neurology (Chicago), 18, 619-625.

Kugelberg, E., and Welander, L. (1956). Heredofamilial juvenile muscular atrophy simulating 
muscular dystrophy. Archives of Neurology and Psychiatry (Chicago), 75, 500-509.

McLeod, J. G., and Prineas, J. W. (1971). Distal type of chronic spinal muscular atrophy. Brain, 94, 703714.

Meadows, J. C., and Marsden, C. D. (1969). A distal form of chronic spinal muscular atrophy. Neurology (Minneapolis), 19, 53-59.

Mulder, D. W., and Howard, J. R. F. M. (1976). Patient resistance and prognosis in amyotrophic lateral sclerosis. Mayo Clinic Proceedings, 51, 537541. 